\title{
New blood: trainee and early career engagement augmenting the society of abdominal radiology experience
}

\author{
Patricia Balthazar $^{1}$ (D) $\cdot$ Aarti Sekhar ${ }^{2} \cdot$ Kirti Magudia $^{3}$ \\ Received: 16 January 2021 / Revised: 20 May 2021 / Accepted: 22 May 2021 / Published online: 31 May 2021 \\ (c) The Author(s), under exclusive licence to Springer Science+Business Media, LLC, part of Springer Nature 2021
}

\begin{abstract}
Many national radiology societies are recognizing the need for early career and trainee engagement as crucial to keeping their societies relevant, active, and invigorated with new ideas. In this descriptive paper, we review the benefits of establishing the Society of Abdominal Radiology's Resident and Fellow Section and Early Career Committee-including our activities and experience, advice for committee structure, and opportunities for growth.
\end{abstract}

Keywords Resident $\cdot$ Early career $\cdot$ Medical society $\cdot$ Committee

\section{Introduction}

Many national radiology societies are recognizing the need for early career and trainee engagement as crucial to keeping their societies relevant, active, and invigorated with new ideas [1-4]. The Society of Abdominal Radiology (SAR) Resident and Fellow Section (RFS) and Early Career Committee (ECC) were created to represent the interests of trainees and abdominal radiologists in their first 7 years out of training, respectively. In this descriptive article, we will review the benefits of establishing an RFS and ECC, our activities and experience, advice for committee structure, and opportunities for growth.

Patricia Balthazar

patricia.balthazar@emory.edu

1 Department of Radiology, Massachusetts General Hospital, Harvard Medical School, 55 Fruit St, Boston, MA 02114, USA

2 Department of Radiology and Imaging Sciences, Emory University School of Medicine, Atlanta, GA, USA

3 Department of Radiology, University of California San Francisco, San Francisco, CA, USA

\section{Resident / fellow sections and early career committees are a win-win for national societies and their members}

RFS and ECC participation brings new blood to national medical societies, with enthusiasm and innovative ideas, as well as sustained loyalty and membership growth. An RFS can aid in the recruitment of well-qualified trainees to the subspecialty and serve as a liaison between the society and residency/fellowship programs, communicating societal benefits and activities to trainees and increasing the likelihood that these trainees will remain society members as they graduate to faculty positions. Similarly, an ECC can ensure that early career members feel welcomed to the society and understand its myriad offerings, increasing enthusiastic participation in all aspects of the society.

Early societal involvement allows for growth and development of the future leaders of the subspecialty. One crucial contribution of RFS and ECC committees is to facilitate networking, a key component for early career success $[5,6]$. As radiology and academia evolved, the traditional long-term mentor-mentee relationship has also needed to evolve, hence the rise of seeking multiple mentors with an array of talents, or "mosaic mentoring"-increasing the range of ideas and opportunities [6, 7]. National societies such as SAR are a perfect substrate to build connections across generations and with colleagues from different institutions. Connecting with other society members at all career levels can provide venues to collaborate on research, explore the job market, and build mentor-mentee relationships. 
Having a dedicated RFS and ECC also promotes opportunities for peer mentorship, such as development of a coaching group within the ECC/RFS leadership, as well as "trickle-up mentorship" where junior members can teach across generations. Examples of this include the "Powerpoint Master Class" session, "Research Toolbox" workshop, and webinar on "Advancing your Career Digitally" all provided opportunities for early career members to teach novel techniques across generations. The "Powerpoint Master Class" was a 1.5-h didactic and interactive presentation by 3-5 speakers. Topics included: developing a story arc, creating visuals using Powerpoint tools and an Apple pen; optimizing tables and graphs; cropping and aligning images; utilizing motion paths and transitions; and demonstrating tools for interactivity such as QR codes and polling. The "Research Toolbox" was a 1.5-h session that offered tips for using excel to do simple statistics, using citation managers, developing a study design, and writing a manuscript. "Advancing your career digitally" was a 1-h online panel presentation by 4 speakers designed to share tips for networking and presenting in the virtual world such as: promoting content through social media, optimizing online presentations, contributing to national societies, and maximizing mentorship experiences.

\section{SAR RFS and ECC activities and experience: creating space for connection and advocating for our members}

In our experience, a combination of informal gatherings and structured events maximizes the opportunity for meaningful communication and relationship building. Social activities that allow for informal networking have been very wellreceived and attended at SAR, decreasing hierarchical barriers and facilitating group bonding. Informal networking activities primarily include happy hours, sports (e.g., basketball, golf, beach yoga, morning run, hiking), and historical tours of the area. These activities are typically scheduled during non-meeting hours and allow for personal connections between members as well as strengthen the sense of community.

Structured events, such as mentorship activities, can be incorporated into the formal schedule for the annual meeting. These might vary from a speed-mentoring luncheon to a small group round-table or a paired 1:1 mentor-mentee event. Each of these require different levels of planning from the committee and the ECC/RFS have collaborated over the past 2 years to have these activities as part of the SAR annual meeting. Examples of past joint ECC/RFS activities and RFS-specific initiatives are summarized in Table 1. ECC/ RFS new member orientation on the first day of the meeting provided an opportunity for first-time attendees to understand the meeting schedule, committees, disease-focused panels (DFPs), workshops, and resort offerings. The RFS dinner with a fellowship director panel allowed trainees to ask questions about fellowship application and career guidance. This was held on the first night of the meeting to also facilitate peer socialization early on in the event.

Advocacy is also a strong mission of the ECC and RFS. The RFS leadership advocated for the approval of a limited number of SAR hands-on workshops, ordinarily special sessions that cost an additional fee, to be provided to trainee members for free. Given the cost constraints for trainees that already paid for the meeting registration and travel, this was extremely well-received. The RFS also surveyed trainees

Table 1 Examples of past early career committee (ECC) and resident and fellow committee (RFS) initiatives for the society of abdominal radiology

Joint ECC/RFS initiatives

Orientation for new members on the first day of meeting

Happy hours with free drinks for RFS and ECC members

Collaborative Research Forum, to link early career investigators with mentors and research collaborators

Speed-mentoring luncheon, a round-table lunch to provide an opportunity for RFS and ECC members to network with well-established SAR leaders

PowerPoint Master Class, to improve presentation skills

Work-life integration panel, to review wellness and efficiency strategies

Sports activities including 6 am fun run, basketball tournament, hiking

RFS-specific initiatives

RFS dinner with a fellowship director panel

Streamlining the membership renewal process for members-in-training

Securing trainee participation in committees and annual meeting activities (e.g., trainee panelists in the Unknown Case Panel)

Surveying members about the new fellowship application process and publishing the data to inform future decisions $[8,9]$

Ensuring a system for extra hands-on workshop spots to be allocated to RFS members 
and fellowship program directors about the new Society of Chairs of Academic Radiology Departments (SCARD) fellowship application process and published the data to inform future decisions $[8,9]$.

In addition to the annual meeting events, there are yearround opportunities for virtual networking and educational webinars. These can increase the society's visibility and advance the career of its members by providing a venue to showcase their expertise. For example, in 2020, the ECC hosted happy hours, as well as a webinar and panel discussion on "Networking and Career Advancement in the Era of COVID-19 and Virtual Meetings".

While these two committees-RFS and ECC-have strong overlapping interests such as mentorship and networking activities, they also have unique needs that are distinct enough to justify two separate committees. Unique interests of ECC members include academic promotion, career development, and faculty wellness and resilience, while unique interests of the RFS include fellowship and job applications, securing trainee participation in society committees and plenary sessions, and promoting the positive experience of trainees at the annual meeting. To coordinate these initiatives, the chairs of RFS and ECC are members of both committees. The two ECC chairs serve as faculty advisors for the RFS, while the chairs of the RFS have a streamlined transition to ECC after graduation. In addition, they report to the same board liaison, which helps to keep the two committee plans aligned while preventing overlap.

\section{Creating an RFS or ECC committee}

To create a new committee, it is important to partner with a more senior member of the society who understands its structure and is able to provide insight and guidance. It is also helpful to use bylaws from the same society or other societies as a model (e.g., Young Physician Section of the American College of Radiology). Writing a clear mission statement, goals, and bylaws allows for institutional memory as well as a sustainable succession plan. This process itself is a valuable lesson in organizational leadership for young members. Herein, we describe the process utilized to create the SAR ECC and RFS.

The SAR ECC was created after a need for early career involvement was recognized by the SAR board in 2017. Two early career radiologists worked with a board member liaison to develop specific goals (Table 2) and a committee structure. The committee includes a chair, a vice-chair (to take over as chair in the second year), 12 members each with a 2-year appointment, and senior advisors. Selection of committee members has prioritized a diversity of race, gender, institution, and type of practice. Since formation and launch at the annual SAR meeting in 2018, the ECC has held monthly meetings and facilitated multiple events described above.

As the ECC gained traction, the next step was creation of an RFS. Under the guidance of the ECC chair, a letter of intent with specific goals (Table 2) was written by two residents to the SAR board outlining how the creation of the RFS would align with the society's strategic goals and offer mutual benefits to the society and its trainee members. The proposed bylaws included the goals of the committee, responsibilities, and governance details.

\section{Governance structure}

For the RFS structure, there are five leadership positions (past-chair, chair, vice-chair, secretary, and communications officer) and an ad hoc steering committee of six members, who assist RFS leadership with specific tasks such as organizing events or selection of new leaders. While most society committees have 2-3 year terms, trainee committees have unique needs given their relatively short training period and involvement of members who may not yet have chosen a specialty. Therefore, it was decided that the majority of RFS
Table 2 Goals of the society of abdominal radiology (SAR) Early career committee (ECC) and resident and fellow section (RFS)

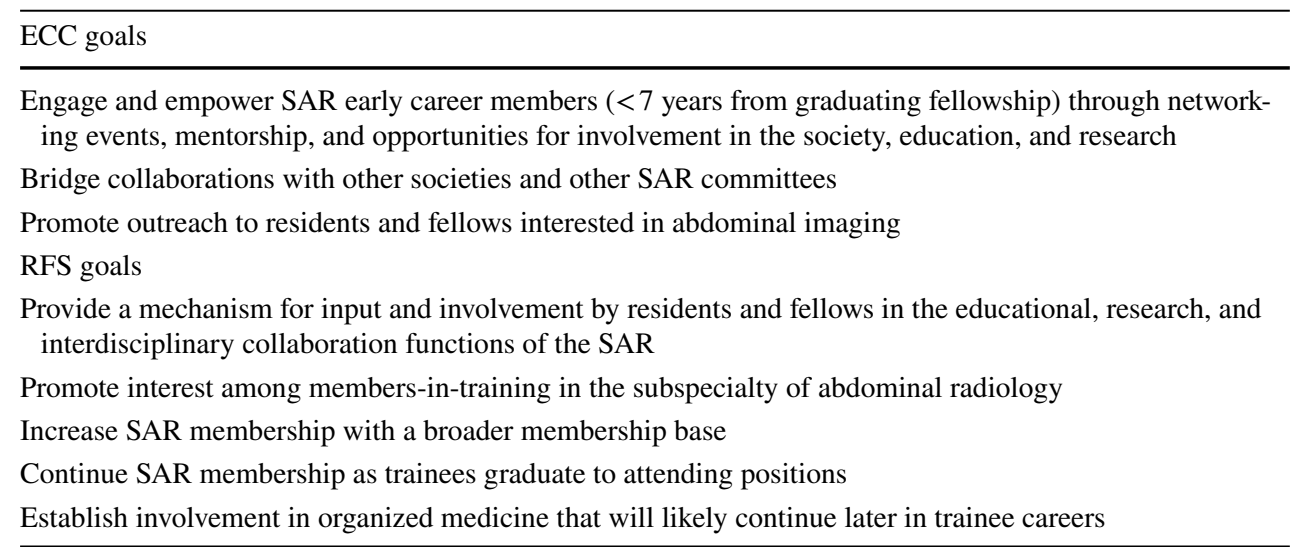


committee members would serve a 1-year term that would allow them to showcase their interests and before transitioning to a longer-term role (such as the 2-3-year chair role, that includes a vice-chair introductory period and the pastchair mentorship/advisory role).

Having a board liaison for both committees allows for better communication with the board, receiving timely updates and understanding the society's priorities. Any activity that uses the society's name (e.g., a survey, social media profile, membership email) must be approved by the board. In addition, organized medicine societies have administrative support personnel, usually from a third-party company. These companies are responsible for planning the logistics of the annual meetings and managing the website. A new committee should have a point of contact with the society's administrative support.

An annual budget should include any expected expenses for the planned activities. It is important to work with the society's administrative representative to know the costs of events inside the annual meeting venue. Since most hotels have exclusive deals and fixed prices for their catering services, these might be more costly than planning activities outside the annual meeting venue, which are often less convenient due to transportation logistics. If cost is an issue, outdoor activities such as hiking or running, utilizing the included hotel amenities or sports events might be a good option. For plans requiring some financial investment (e.g., activities requiring a rental or expert personnel), a sign-up form and additional cost might be required.

\section{Recruitment and external communication}

Recruitment for both ECC and RFS leadership roles starts with an email blast and social media call for volunteers to serve. Interested members fill out an online form asking how joining these committees align with their future career goals and how they can contribute to the advancement of the SAR ECC and RFS. The answers are reviewed by the committees, who vote for volunteers suitable for each available role. Trainees interested in volunteering for a SAR RFS leadership role should become SAR members (which is free for members-in-training) and submit their application during the call for volunteers, which is sent out by email to all trainee members prior to the annual meeting.

Having a separate social media account can be beneficial for distribution of information that is relevant to the RFS/ECC. This must be approved by the board and it allows for faster communication with members compared to the overarching society profile because it can be managed internally rather than through a third-party group. The society's administrative support can help coordinate society-wide email blasts. It is also important for the RFS/ECC to have a landing page on the society's website and to work with society administration to keep it up to date.

\section{Conclusion}

In summary, the creation of dedicated RFS and ECC committees have augmented the SAR experience by providing a platform for representation of these groups and facilitating cross-generational interaction. These groups have organized networking, mentorship, training, and career development activities that have increased membership engagement at the annual meeting and year-round. Developing and implementing a new committee involves thoughtful consideration toward the committee's goals, structure and bylaws, but is in itself a valuable lesson in organizational leadership for younger members. Potential future initiatives from the SAR RFS and ECC include streamlining the trainee membership renewal and transition to full membership processes, having dedicated RFS and ECC tracks for the annual meeting program, and developing a longitudinal mentorship program.

\section{Declarations}

Conflict of interest All authors declare that they have no conflict of interest.

\section{References}

1. Young and Early Career Professional Section I American College of Radiology. Accessed December 26, 2020. https://www.acr.org/ Member-Resources/yps

2. SIR RFS. Accessed December 26, 2020. http://rfs.sirweb.org/

3. Resident and Fellow Section I American College of Radiology. Accessed December 26, 2020. https://www.acr.org/MemberResources/rfs

4. RSNA Resident and Fellow Committee. Accessed December 26, 2020. https://www2.rsna.org/timssnet/About/committee.cfm?c= 00521716

5. Bredella MA, Alvarez C, O'Shaughnessy SA, Lavigne SD, Brink JA, Thrall JH. Radiology Mentoring Program for Early Career Faculty-Implementation and Outcomes. J Am Coll Radiol. Published online October 5, 2020. https://doi.org/10.1016/j.jacr.2020. 09.025

6. Blanco MA, Qualters DM. Mutual mentoring: Effect on faculty career achievements and experiences. Med Teach. 2020;42(7):799805. https://doi.org/10.1080/0142159X.2020.1736535

7. Ansmann L, Flickinger TE, Barello S, et al. Career development for early career academics: Benefits of networking and the role of professional societies. Patient Education and Counseling. 2014;97(1):132-134. https://doi.org/10.1016/j.pec.2014.06.013

8. Magudia K, Sugi MD, Balthazar P, Donelan K, Gupta RT, Maturen KE. The SCARD Fellowship Policy and the Abdominal Imaging Fellowship: A Follow-up Survey After the First Year. Acad Radiol. Published online December 16, 2020. https://doi. org/10.1016/j.acra.2020.12.004 
9. Magudia K, D Sugi M, Balthazar P, et al. Prospects of a Fellowship Match for Abdominal Imaging: A National Survey by the Society of Abdominal Radiology. J Am Coll Radiol. Published online February 24, 2020. https://doi.org/10.1016/j.jacr.2020.02. 003
Publisher's Note Springer Nature remains neutral with regard to jurisdictional claims in published maps and institutional affiliations. 